\title{
POLUIÇÃO DO AR NO BAIRRO CENTRO DE SANTA MARIAIRS: variáveis geourbanas e geoecológicas
}

\author{
Msc. José Renato Rocha \\ Universidade Salgado de Oliveira- UNIVERSO \\ Av. Evaldo Behr, 22 - Residencial Novo Horizonte, CEP: 97110-801, Santa Maria (RS)-Brasil \\ zegeografia@gmail.com \\ Prof. Dr. Adriano Severo Figueiró \\ adriano.geo@terra.com.br
}

\begin{abstract}
RESUMO
Esta pesquisa teve como objetivo verificar a concentração de material particulado nas principais ruas e avenidas do bairro Centro de Santa Maria/RS, relacionando, como variáveis de influência, as condições geoecológicas e a estrutura urbana local. A metodologia de pesquisa caracterizou-se pela elaboração de um zoneamento ambiental do bairro Centro com enfoque na qualidade do ar. Posteriormente, realizou-se a medição das concentrações de material particulado, em trabalho de campo e dados secundários referentes ao material particulado inalável extraídos da FEPAM/RS. A terceira etapa consistiu no cruzamento dos dados de material particulado com o mapa de zoneamento, com vistas a estabelecer possíveis correlações e, também, testar a eficácia do zoneamento ambiental no que se refere à qualidade do ar. A última etapa consistiu na análise e cruzamento dos dados referentes às concentrações de material particulado e a sucessão habitual dos tipos de tempo em Santa Maria/RS.
\end{abstract}

Palavras-chave: Planejamento ambiental, poluição atmosférica, vegetação urbana

\begin{abstract}
The goal of this research was to verify the concentration of particulate matter in the principals' streets and avenues of Centro district of Santa Maria city/RS, making an association between geoecological conditions and the local urban structure. The research methodology was characterized for the environmental zoning's elaboration in the Centro district with focus on the air's quality. Lately, an investigation of particulate matter was made, using field work and secondary data related to inhale particulate matter, consulted in FEPAM/RS. The third stage consists in an intersection between particulate matter's data and the zoning map, with the intention of establish possible correlations and test the environmental zoning's efficiencies. The last stage consists in analyses of the datas intersectioned relative to particulate matter concentrations suitable with the environmental zoning.
\end{abstract}

Key Words: Environmental Planning, atmospheric polution, urban vegetetation

\section{RESUMEN}

La meta de esta investigación fue verificar la concentración de material particulado en las calles y avenidas principales de barrio Centro de Santa Maria - RS, mientras haciendo una asociación entre las condiciones geoecológicas y la estructura urbana local. La metodología de la investigación se caracterizó en la elaboración de un zoneamiento medioambiental en el barrio Centro con el enfoque de la calidad del aire. Mas adelante, una investigación de material particulado fue hecho, mientras a usando el trabajo del campo y los datos secundarios de material particulado compilados en FEPAM/ RS. La tercera fase consistió en una intersección entre los datos de materia particulado y lo zoneamiento, con la intención de establezca las posibles correlaciones y pruebe las eficacias de la división en zonas medioambientales. La última fase consistió en las análisis y cruzamientos de las concentraciones con la división en zonas medioambientales.

Palabras-clave: Planificación ambiental, polución atmosférica, vegetación urbana

\section{INTRODUÇÃO}

A urbanização nos dias de hoje tornou-se um processo irreversível, principalmente após a revolução industrial que ocorreu no século XIX, se tornando praticamente um fenômeno mundial no século seguinte. Na Inglaterra, por exemplo, em 1960, 80\% da população concentrava-se em áreas urbanas (NASCIMENTO, 1992). Ainda, conforme Mendonça (1994), nos países não desenvolvidos ou emergentes, a urbanização se desenvolveu de forma desordenada, principalmente a partir da década de 40, como resultante do êxodo rural, que deu origem a várias novas cidades e ao crescimento das já existentes. Destituídas de um planejamento urbano adequado, elas vêm apresentando ambientes onde a degradação física e social são flagrantes. 
No que tange aos problemas relacionados a esse uso insustentável do meio ambiente urbano, a qualidade do ar em nossas cidades, principalmente em grandes centros urbanos, e nas últimas décadas, tem sido alvo de grandes discussões, tanto no meio acadêmico, por cientistas, intelectuais, quanto também em noticiários, jornais e revistas de todo mundo. Mas o interesse por este tema, muitas vezes fica só nas discussões que envolvem segmentos restritos da sociedade, fazendo com que a maioria da população não tenha acesso ao conhecimento necessário para a tomada de consciência ou para a criação de instrumentos efetivos de reivindicação.

Observa-se na bibliografia brasileira, especialmente no que se refere aos trabalhos de cunho geográfico, um leque não muito grande de trabalhos e estudos realizados. Para cidades de porte médio e grande, este assunto deveria receber maior atenção por parte dos planejadores, gestores urbanos e ambientais.

A busca da relação existente entre os fatores de origem natural e os de origem antrópica, com a quantidade de material particulado nas principais ruas e avenidas da cidade, pode levar a resultados interessantes no que se refere à qualidade ambiental e qualidade de vida nas áreas de maior concentração urbana (JACKSON, 2003).

Neste sentido, o objetivo principal desta pesquisa foi o de verificar a concentração de material particulado nas principais ruas e avenidas do bairro Centro de Santa Maria/RS, relacionando, como variáveis de influência, as condições geoecológicas (condições atmosféricas predominantes, presença ou não de arborização, principais ventos) e a estrutura urbana local (fluxo de veículos, direção do arruamento).

\section{RECORTE ESPACIAL DA PESQUISA}

O município de Santa Maria está localizado na região central do estado do Rio Grande do Sul, mais precisamente na Depressão Periférica Sul-Riograndense, nas coordenadas geográficas de $29^{\circ}$ $39^{\prime}$ a $29^{\circ} 43^{\prime}$ de latitude sul, e $53^{\circ} 50^{\prime}$ a $53^{\circ} 45^{\prime}$ de longitude oeste.

A área de estudo (figura 1) situa-se na transição entre os campos sulinos e a floresta estacional decidual , que acompanha o desenho do rebordo do planalto gaúcho.

Sua circulação atmosférica regional é, na grande maioria dos dias, controlada por sistemas atmosféricos extra-tropicais (cerca de $90 \%$ dos dias do ano), principalmente sob a forma de Massa Polar Atlântica ou Massa Polar Velha. São poucos os dias em que se tem o domínio climático controlado pela Massa Tropical Atlântica, que se restringem basicamente ao período do verão (SARTORI, 1993). Apresenta ainda, características de invernos frios, com média entre $13 \mathrm{C}^{\circ} \mathrm{e}$ $15 \mathrm{C}^{\circ}$, e verões quentes, com a média do mês mais quente superior a $24 \mathrm{C}^{\circ}$. Os índices anuais de pluviometria situam-se na casa dos $1750 \mathrm{~mm}$ em média.

A região central da cidade está assentada sobre uma área colinosa, identificada como a área mais elevada do sítio urbano de Santa Maria, com 150 metros de altitude e declividades entre 6,9 e $8,3 \%$, formando um divisor de águas, mais precisamente na Rua do Acampamento (SARTORI, 1979).

No que se refere aos principais tipos de ventos presentes na cidade, de acordo com Sartori (1984), os mais importantes em Santa Maria são os de leste (predominantes em freqüência), os de norte e noroeste (mais quentes e de maior velocidade), e os de sul e sudeste (mais frios e segundos em freqüência). Ainda neste sentido, a topografia da cidade, com o rebordo do planalto situado a norte, e alongando-se no sentido leste-oeste, é responsável pela canalização do vento em direção à cidade, auxiliando na predominância dos ventos de leste. 


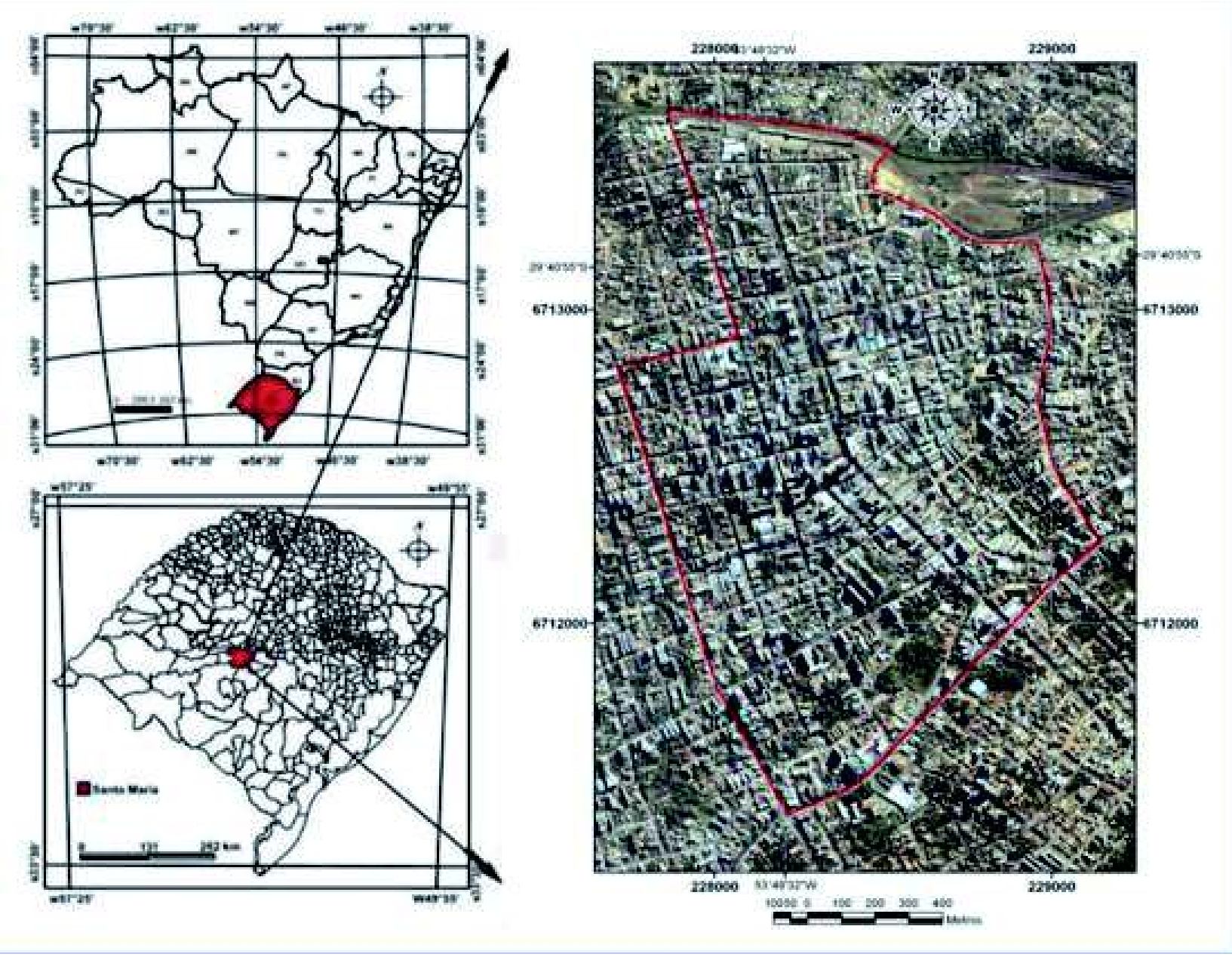

Figura 1: Localização da área em estudo.

\section{METODOLOGIA}

O desenvolvimento do trabalho proposto seguiu quatro grandes momentos:

$1^{\circ}$ - Elaboração de um zoneamento ambiental do bairro Centro de Santa Maria, com enfoque na qualidade do ar:

Para a realização deste zoneamento ambiental foram levados em conta os seguintes critérios:

. Mapa de cobertura vegetal, onde foi quantificada toda a cobertura vegetal de porte arbóreo existente no bairro Centro, visível na imagem de satélite IKONOS de escala 1:10.000 do ano de 2005.

. Mapa do fluxo de ônibus, onde foram identificadas e quantificadas as principais rotas de ônibus que percorrem o bairro Centro de Santa Maria. O levantamento destes fluxos foi realizado através das informações obtidas diretamente nas empresas de transporte urbano da cidade, de forma a contemplar a variabilidade do trânsito nos diferentes meses do ano e também dias da semana.

. Identificação a campo dos eixos urbanos do bairro Centro que propiciam fluxos de vento mais intensos, de acordo com os tipos de tempo mais freqüentes na atmosfera da cidade.

Para a elaboração destes mapas foi utilizado o Software Spring, versão 3.3 para windows e também o sofftware Corel Draw 12, o qual serviu para a edição final dos mapas. 
. $\underline{\mathrm{O} \text { zoneamento ambiental levou em conta as zonas de alta, média e baixa fragilidade em re- }}$ lação ao potencial de concentração de material particulado.

$2^{\circ}$ - Levantamento dos dados referente ao material particulado:

Esta etapa consistiu em verificar a quantidade de material particulado (poeira), nas principais ruas e avenidas do bairro Centro da cidade, e sua relação com os principais tipos de tempo presentes na atmosfera da cidade de Santa Maria.

Devido a falta de equipamentos mais precisos optou-se pela elaboração de um material de coleta artesanal. Neste sentido, segundo Danni-Oliveira (1999), a construção de equipamentos alternativos tem viabilizado trabalhos acadêmicos, possibilitando o desvendar do clima e dos fenômenos urbanos de muitas cidades brasileiras.

A técnica utilizada consistiu na preparação e distribuição, no interior da área de estudo, de plaquetas de retenção de material particulado (figura 2). Essas plaquetas são de fácil construção, utilizando-se uma base retangular de ferro, onde é fixado uma fita adesiva dupla-face para que fique "grudado" o material particulado depositado.

Após algum período de exposição, essas plaquetas fornecem dados referentes ao total de material particulado, a partir da diferença de peso entre antes e após a exposição. O tempo padrão de coleta foi de quatro dias.

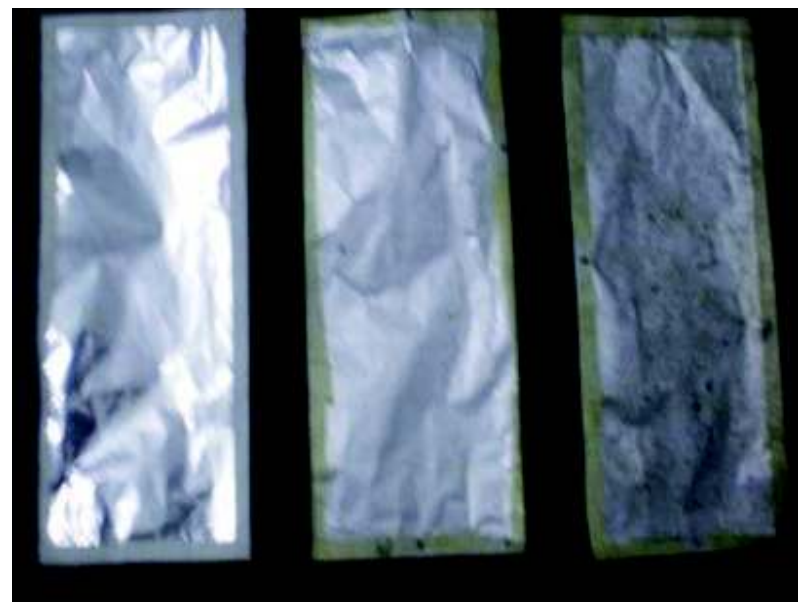

Figura 2: Deposição de material particulado nas placas de coleta, uma limpa (a esquerda) e outras duas sujas após a exposição

Para que a coleta de material particulado pudesse contemplar o objetivo central proposto nessa pesquisa, foram escolhidas algumas ruas e avenidas para as coletas, de forma que envolvessem todas as variáveis (situações) possíveis definidas como atenuantes ou dispersoras de material particulado. Estes locais que selecionados para as coletas podem ser visualizados na figura 3.

Neste sentido, o instrumento de coleta de material particulado foi distribuído tanto em ruas e avenidas com presença de vegetação arbórea, quanto em locais de escassa arborização, para verificar a existência de diferenças nas quantidades de deposição, como decorrência da capacidade de diferenças de "filtragem" na vegetação.

Foram escolhidas também ruas com alto e baixo fluxo de veículos, tendo como princípio a idéia de que os veículos, principalmente os movidos a óleo diesel, são os principais responsáveis pela origem e emissão do material particulado que se encontra nas ruas do bairro Centro, uma vez que o mapa detalhado de uso do solo (figura 4) no bairro não evidenciou outra fonte de emissão.

Também foram utilizados os dados fornecidos pela FEPAM/RS, referente ao período de julho de 2004 até meados de janeiro de 2007, coletados junto a Estação móvel de monitoramento da qualidade do ar, situada na Avenida Borges de Medeiros e Presidente Vargas. 
$\underline{3^{\circ}-\text { Cruzamento dos dados: }}$

A terceira etapa consistiu no cruzamento dos dados de material particulado com o mapa de zoneamento previamente elaborado, com vistas a estabelecer possíveis correlações e, também, testar a eficácia do zoneamento ambiental no que se refere à qualidade do ar na cidade de Santa Maria.

Os cruzamento utilizados foram os seguintes: vegetação $X$ fluxo de ônibus, vegetação $X$ ventos, fluxo de ônibus $\mathrm{X}$ ventos.

Salienta-se que para a análise da significância dos resultados de correlação encontrados, utilizou-se o coeficiente de Pearson, onde foram analisadas as correlações que obtiveram índice superior a 0,60. Dessa forma, segundo Pocinho \& Figueiredo (2004 apud FIGUEIRÓ, 2005), os coeficientes (r) situados acima de 0,6 , indicam correlação estatisticamente significativa entre as variáveis correlacionadas.

$\underline{4^{\circ} \text { Análise e cruzamento dos dados referentes as concentrações de material particulado e os }}$ tipos de tempo em Santa Maria/RS;

Buscando-se relacionar os episódios de maior concentração de material particulado inalável, fornecidos pela FEPAM/RS, com a sucessão habitual dos principais tipos de tempo em Santa Maria, utilizou-se da proposta desenvolvida por Sartori (1993), onde a autora tipifica os principais tipos de tempo que ocorrem no inverno gaúcho.

\section{RESULTADOS E DISCUSSÃO}

Mapeamento das variáveis utilizadas na elaboração do zoneamento ambiental do bairro Centro.

Quando analisada a cobertura vegetal de porte arbóreo do bairro Centro, verifica-se que são poucos os locais em que se tem conexão entre os elementos arbóreos, salvo exceção do canteiro central da Avenida Rio Branco e parcelas da Avenida Presidente Vargas e Medianeira, conforme visualiza-se na figura 5. Neste sentido, verifica-se que grande parte dos elementos arbóreos encontram-se dispersos, com as árvores restritas a calçadas e alguns pequenos espaços.

Foi possível verificar, através do mapeamento da cobertura vegetal arbórea, um índice de $8,23 \%$ de cobertura arbórea para o bairro Centro, valor este muito abaixo dos $30 \%$ sugeridos por Lombardo (1985), como recomendáveis para proporcionar um adequado balanço térmico.

Quanto ao mapa de linhas de ônibus, verifica-se que justamente essas regiões que apresentam um "deserto" arbóreo coincidem com ruas de grande fluxo de ônibus, tais como a Rua do Acampamento, Riachuelo, General Neto e André Marques (figura 5). Esse fato faz com que as partículas emitidas por carros e ônibus tenham ainda maior contato com a população que circula nestas ruas, uma vez que a inexistência da vegetação não produz o efeito de barreira a desse material inalável.

\section{Zoneamento ambiental quanto ao potencial de deposição de material particulado para o bairro Centro de Santa Maria}

As variáveis utilizadas para a demarcação das ruas e avenidas mais propícias ao acúmulo de particulados foram: presença de vegetação, fluxo de ônibus, e ainda o sentido do arruamento. Estas duas primeiras variáveis foram ainda definidas em classes, sendo que foi realizado cruzamentos entre elas para que se encontrassem as ruas ou avenidas com maior pré-disposição a deposição de particulados.

A variável vegetação foi definida em função da sua significativa presença, em ruas "com vegetação" e ruas "sem vegetação".

Para a variável fluxo de ônibus, foram definidas duas classes quanto a intensidade de tráfego, sendo considerada de "baixo fluxo" a rua com até 23 linhas de ônibus. Estabeleceram-se como ruas de "alto fluxo" as que ultrapassam esse valor ( $>23$ linhas).

Mercator - volume 9, número 18, 2010: jan./abr. 


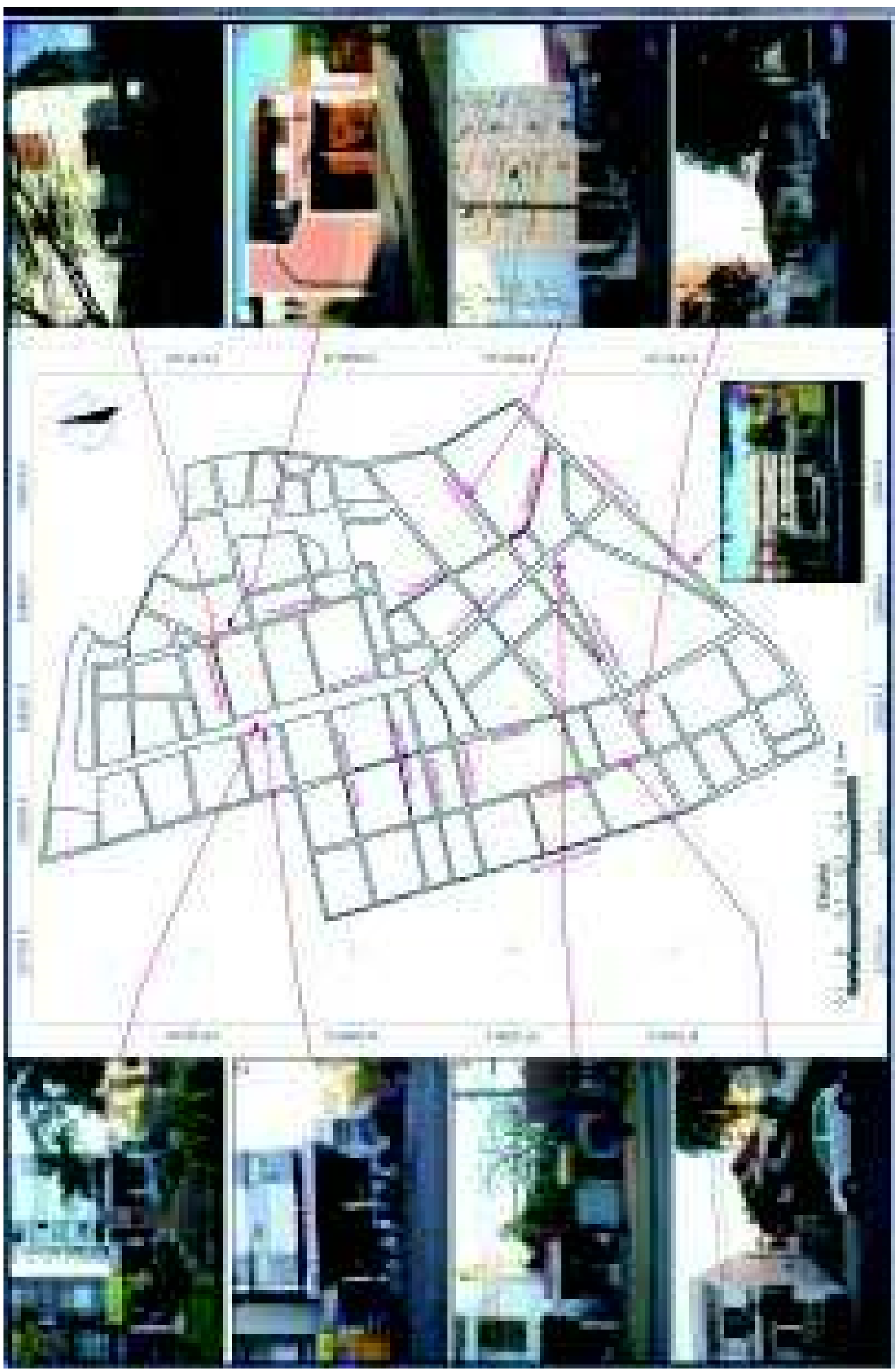

Figura 3 - Mapa distribuição dos pontos de coleta de material particulado no bairro Centro de Santa Maria 


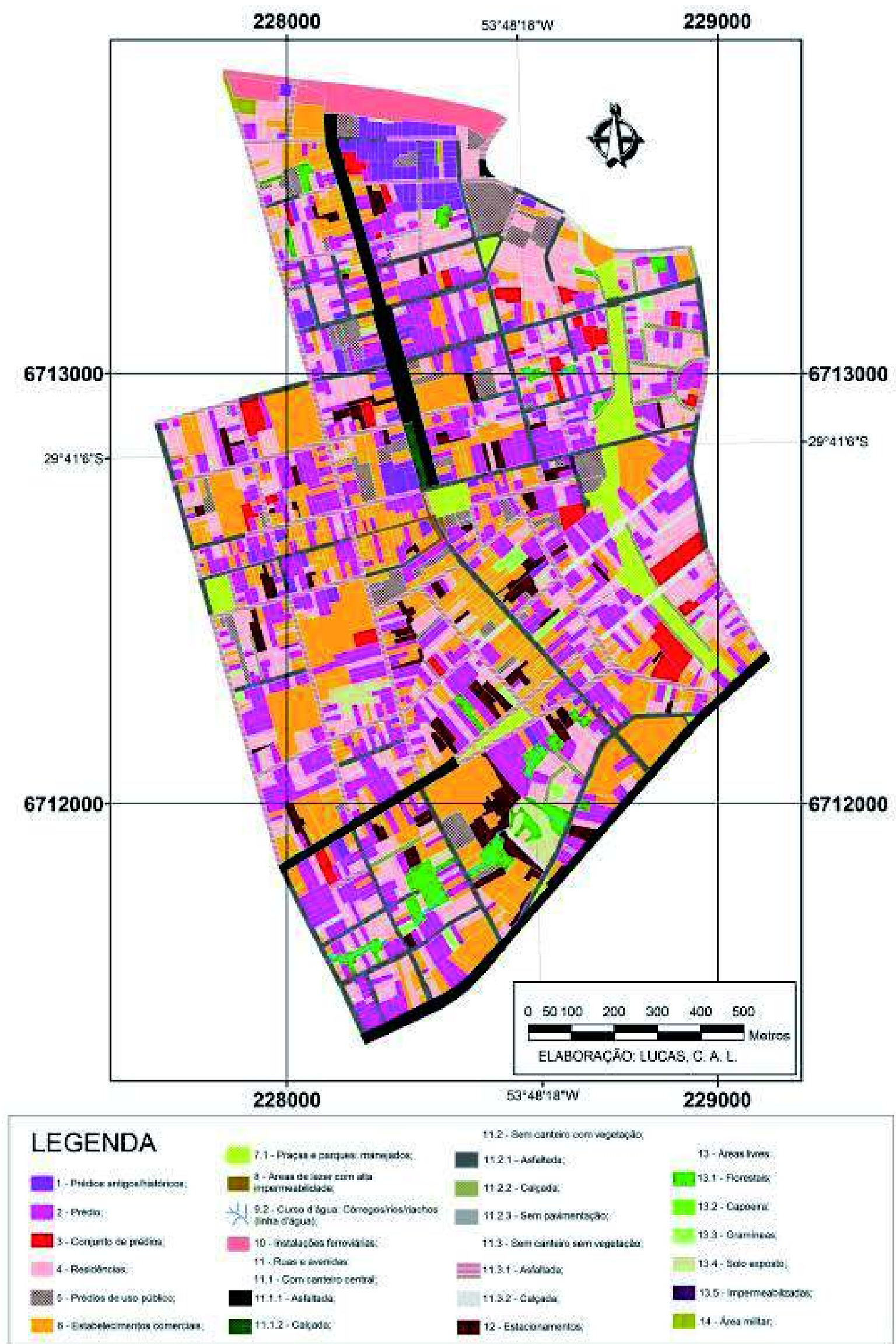

Figura 4 - Mapa detalhado de uso do solo no bairro centro de Santa Maria 
Por fim, para a variável direção do arruamento, utilizou-se somente de duas direções, sendo as ruas com direção predominante $(\mathrm{N}-\mathrm{S})$ e ruas com direção predominante (L-O). Salienta-se que foi utilizada como variável a direção predominante da rua, devido à relação que o sentido do arruamento possui tanto para a canalização dos ventos, como também atuando na forma de barrar a velocidade destes, o que vem a interferir na deposição ou dispersão dos poluentes.

Neste sentido, segundo Sartori (1979) o fato de as ruas da malha urbana de Santa Maria estarem dispostas no sentido ENE-WSW e SSE-NNW favorece a ventilação natural, com canalização dos ventos predominantes de leste e sudeste, associado ao domínio das massas polares (MPA), bem como ventos quentes de N e NW ou mais frios de S e SE. Sartori (1993) afirma ainda, que os ventos mais intensos são os de norte e nordeste das fases pré-frontais.

Baseado nesta relação entre ventos e direção do arruamento, inferiu-se como variável de menor predisposição ao acúmulo das deposições de material particulado as ruas e avenidas que possuem arruamento no sentido leste-oeste (figura 6).

\section{Análise dos dados absolutos referente aos valores das concentrações verificados nas ruas $e$ avenidas do bairro Centro.}

Para que se pudesse buscar uma variação temporal das concentrações de material particulado, foram realizadas coletas nos nove pontos determinados, em diversos períodos do ano de 2008 , sendo a primeira coleta realizada no mês de novembro do ano de 2007 e a última no mês de junho de 2008. Neste período foi possível a realização de 13 coletas, dependentes de condições meteorológicas favoráveis.

A partir dos valores das concentrações encontradas, realizou-se o cálculo da média para todas as unA partir dos valores das concentrações encontradas, realizou-se o cálculo da média para todas as unidades de coleta, como se pode visualizar na figura 7. A partir disto, foi possível verificar que a Rua André Marques obteve os maiores valores de poeira depositada, seguida da Avenida Medianeira, Avenida Rio Branco, Rua Valandro e Acampamento, respectivamente.

Quando realizada a comparação entre os valores das concentrações obtidas nas ruas e avenidas verifica-se que os maiores valores de poeiras foram obtidos em uma rua de médio fluxo de ônibus (24 a 30 linhas de ônibus), com presença praticamente inexpressiva de arborização.

$\mathrm{Na}$ análise dos valores das concentrações da Rua André Marques ao longo dos episódios de coleta, pode-se verificar 4 coletas que apresentaram valores que se destacaram com altas concentrações. São as coletas realizadas no mês de novembro de 2007, do dia 14 até o dia 17, fevereiro de 2008 e as duas coletas do mês de abril de 2008.

Através do mapa de interpolação de isolinhas pode-se verificar espacialmente as concentrações de material particulado de acordo com a localização dos pontos de coleta (figura 8).

O cruzamento destes dados com os tipos de tempo que ocorreram neste período, não demonstrou nenhuma correlação significativa, o que nos levou a acreditar que a quantidade de partículas emitidas pelos veículos automotores, bem como a própria poeira ressuspensa pelos ônibus e carros, possui maior influência nas concentrações encontradas nas plaquetas do que propriamente as características dos tipos de tempo verificados.

Os locais de coleta que se destacaram como de maiores concentrações de poeiras, Rua André Marques, Avenida Medianeira, Avenida Rio Branco, Rua Serafim Valandro e Acampamento possuem diversas características diferentes entre elas.

No caso da rua André Marques, o vento que é canalizado suspende uma grande quantidade de poeiras que, por transporte de gravidade da chuva, ficam depositadas na parte "baixa" da rua, sendo ressuspensas pela corrente de vento e projetadas para os locais onde a sua energia cinética tende a diminuir, ou seja, na parte alta da rua, coincidindo com a região onde ficou instalada a plaqueta de coleta, o que pode ser melhor compreendido a partir do perfil topográfico desta rua (figura 9). 

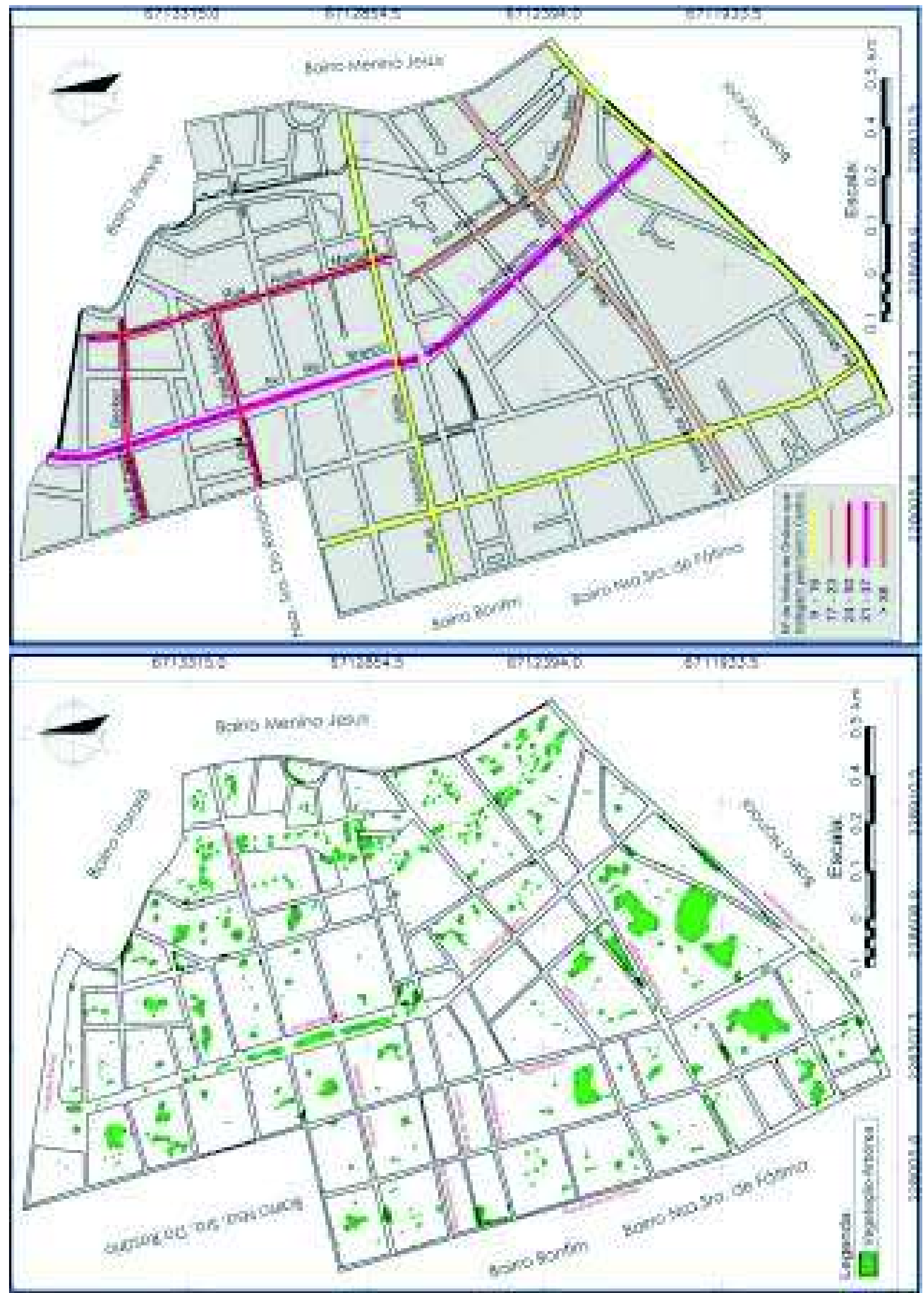

Figura 5 - Mapa da cobertura vegetal arbórea e das principais rotas de ônibus do bairro Centro de Santa Maria/RS. 


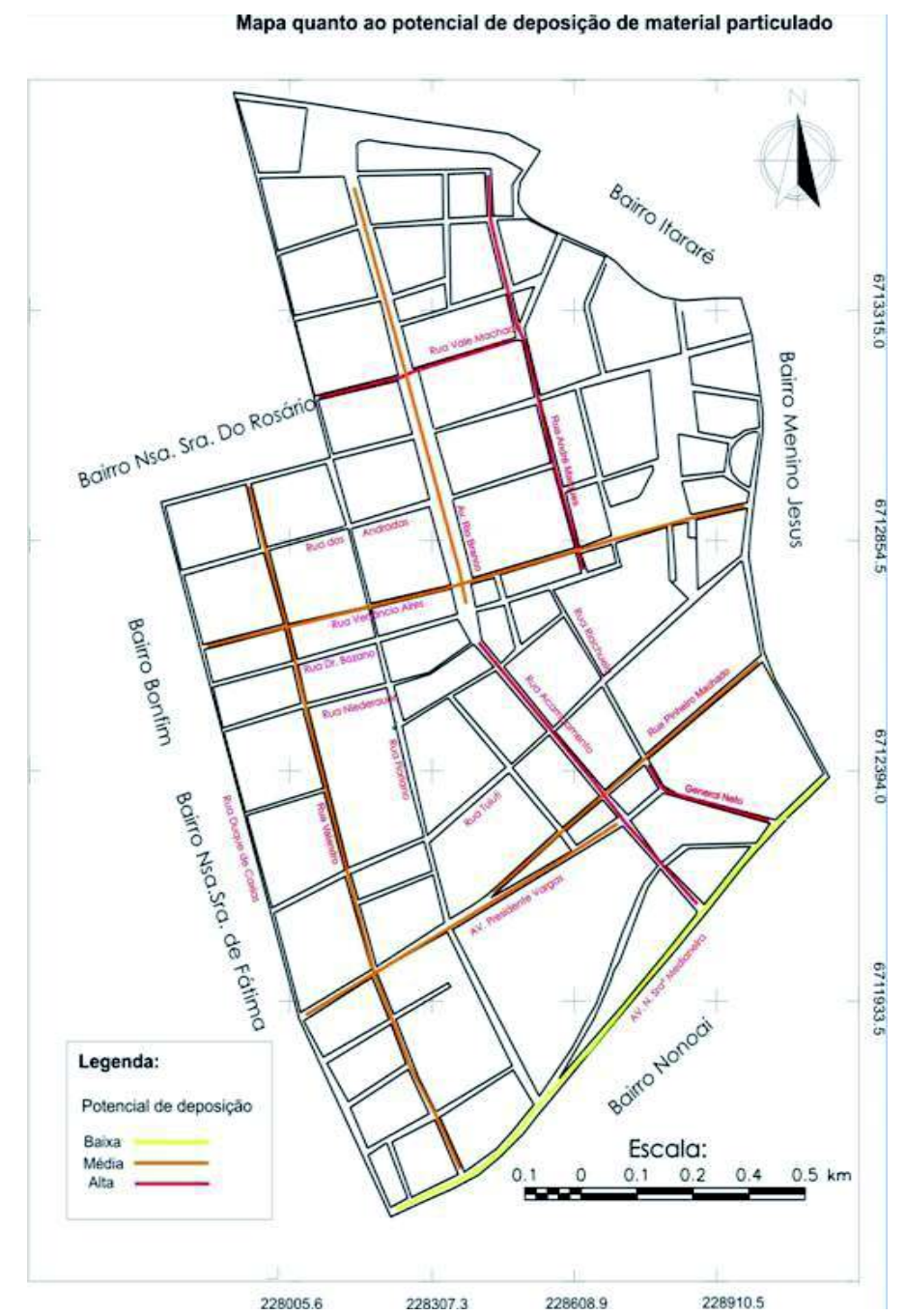

Figura 6 - Mapa de zoneamento ambiental quanto a deposição de material particulado.

A Avenida Medianeira possui uma realidade bem diferenciada quanto as variáveis analisadas, tais como maior presença de arborização, menor número de linhas de ônibus, maior verticalidade dos edifícios, embora o local de coleta não esteja localizado entre prédios altos, funcionando como um receptor de poeiras de diversas direções.

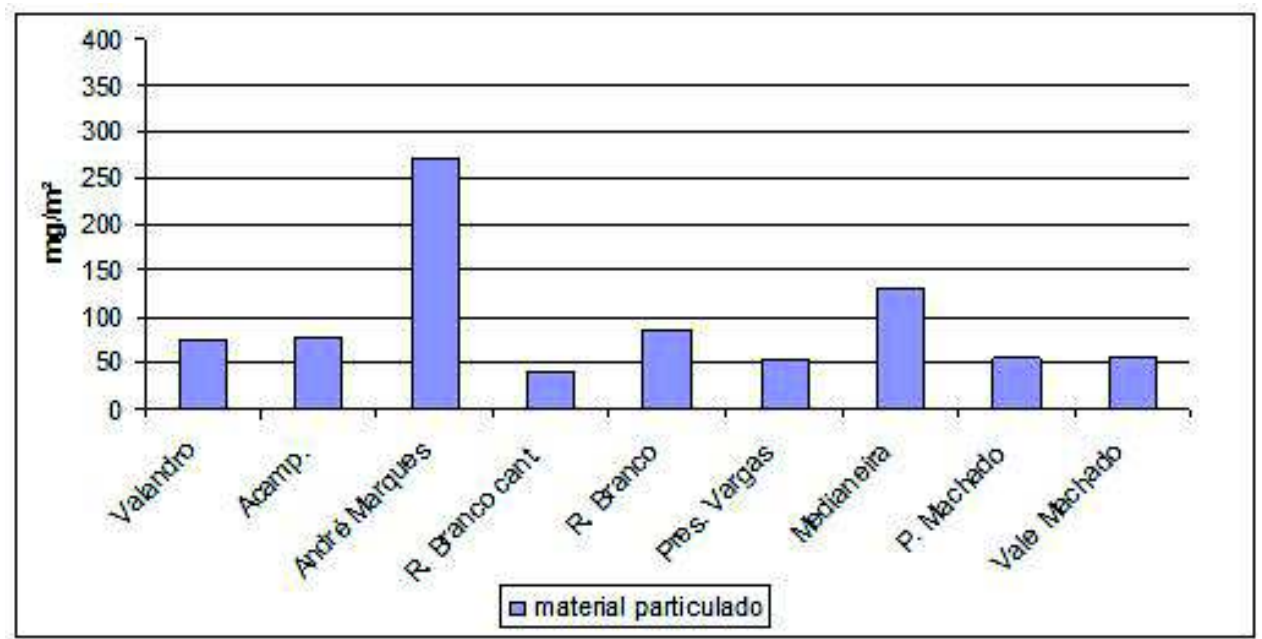

Figura 7 - Valores médios para as concentrações de material particulado ao longo de todos os episódios coletas. 
Deposiçāo média de material particulado $\mathrm{mg} / \mathrm{cm}^{2}$

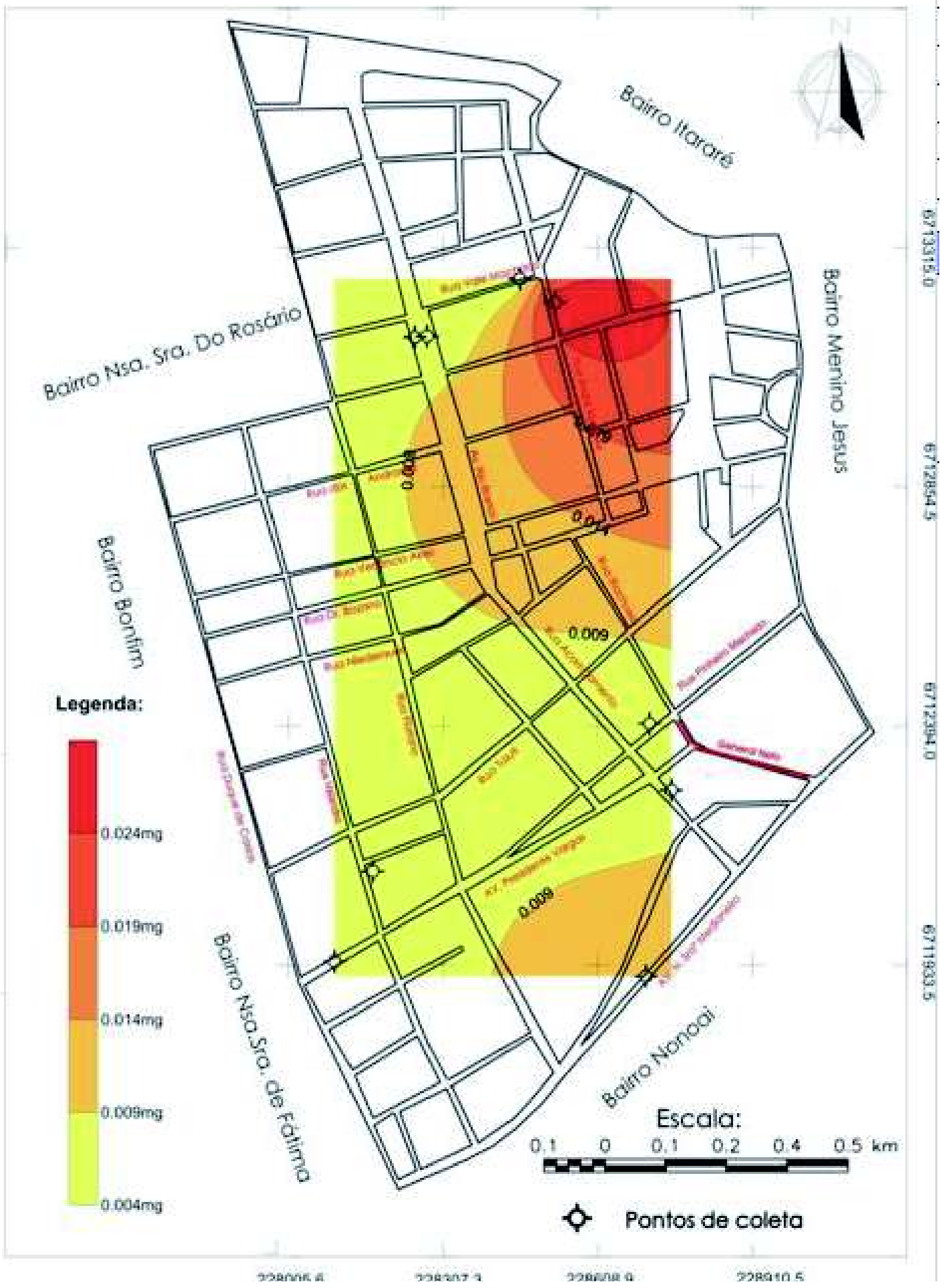

Figura 8 - Interpolação dos dados de deposição média de material particulado nas ruas e avenidas utilizadas como ponto de coleta no bairro Centro $\left(\mathrm{mg} / \mathrm{cm}^{2} / \mathrm{dia}\right)$.

Apesar destas diferenças, quando analisado o perfil topográfico da Avenida Medianeira, podemos observar uma realidade bastante parecida com o que ocorre na Rua André Marques, onde as grandes concentrações de poeiras podem ser conseqüência da deposição de poeiras na parte mais alta da Avenida. Como conseqüência, o que é trazido para cima, devido à influência dos ventos que 
são canalizados desde as partes mais baixas, faz com que grandes quantidades de poeiras fiquem depositadas na sua parte alta, devido à diminuição da energia cinética, como pode ser confirmado na análise do perfil topográfico da Avenida Medianeira (figura 10).

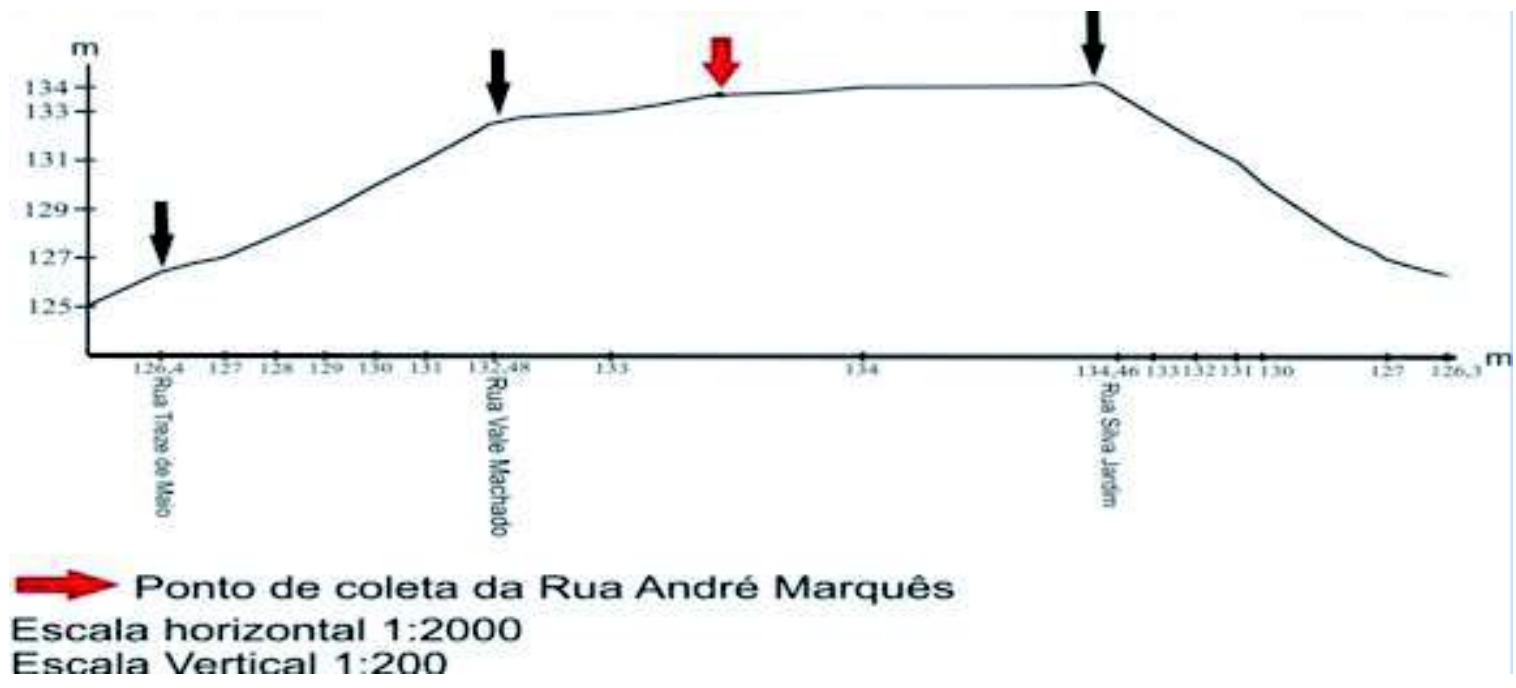

Figura 9 - Perfil topográfico de um trecho da Rua André Marques.

JJá as áreas que se localizam à montante destes pontos de ruptura de declive acabam recebendo menor volume de material depositado devido à diminuição da carga de material suspenso, na medida em que reduz o nível de energia do ar em circulação. É o que acontece com a rua do Acampamento, onde os níveis de deposição foram considerados como baixos quando comparados a outros pontos de coleta próximos, a exemplo da rua Serafim Valandro.

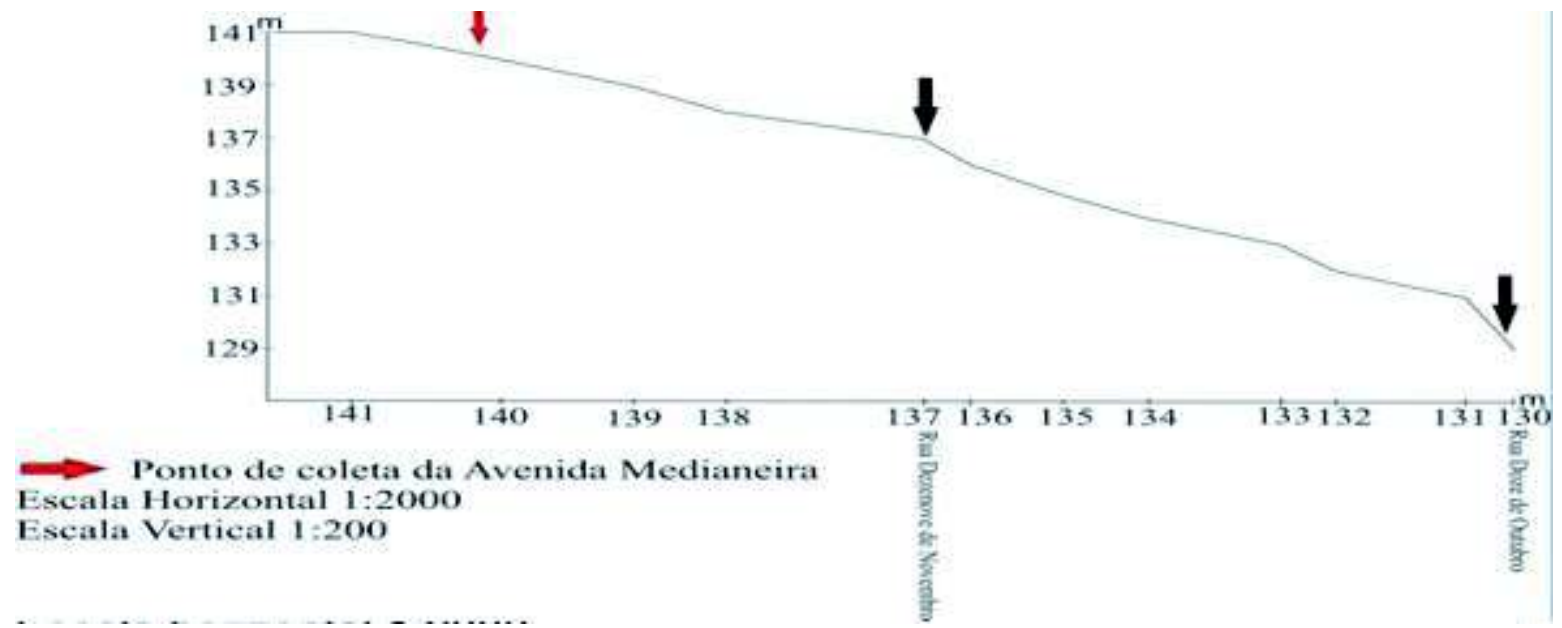

Figura 10 - Perfil topográfico de um trecho da Avenida Medianeira.

De uma forma geral, verificou-se que os locais de maiores índices de poeiras possuem orientação (N-S), devido à direção preferencial do arruamento. A direção predominante Leste só assume realmente uma maior importância nas áreas periféricas da cidade ou então nas partes mais altas dos edifícios. Porém, no nível do chão, o comprimento da rua, associado à capacidade de aceleração do vento, faz com que uma maior quantidade de poeiras seja ressuspensa no sentido N-S, enquanto que as ruas que se projetam no sentido E-W tendem a apresentar menor circulação/deposição de material particulado.

Esta tendência de maior suspensão de particulados nas ruas de orientação N-S, tende a ser alterada nas ruas onde há maior presença de vegetação, devido à retenção das poeiras e dos materiais particulados emitidos por veículos (embora estas emissões, com tamanho inferior a $10 \mu \mathrm{g}$, não sejam possíveis de quantificar pelo método de plaquetas adotado) e outra fontes. Assim, constatou-se uma 
clara relação entre as menores concentrações de poeiras depositadas e a presença de arborização como, por exemplo, na avenida Rio Branco, no canteiro Central, próximo às árvores de grande porte.

Relação entre as concentrações de material particulado e os tipos de tempo da cidade de Santa Maria.

O grau de poluição de uma determinada região deve-se, em grande parte, às condições meteorológicas locais. Portanto, para a avaliação das concentrações dos poluentes é imprescindível o conhecimento dos fenômenos que regem a variabilidade atmosférica (MITKIEWICZ; MELO, 2002).

Neste sentido, utilizou-se dos dados de material particulado cedidos pela Fundação Estadual do Meio Ambiente (FEPAM/RS), coletados através da estação automática localizada na esquina da Avenida Borges de Medeiros com a Avenida Presidente Vargas. Procurou-se relacionar as concentrações de material particulado com a sucessão habitual dos tipos de tempo que predominaram na atmosfera da cidade neste mesmo período.

Para caracterizar adequadamente o tipo de tempo, bem como a massa de ar que dominava a cidade quando das elevadas concentrações de material particulado, utilizou-se dos dados disponibilizados pela estação meteorológica situada na UFSM. A partir disso, passou-se a identificar o tipo de tempo atmosférico predominante em cada um dos dias onde os valores de concentração de material particulado ficaram acima de $50 \mathrm{mg} / \mathrm{m}^{3}$.

Utilizando-se destes critérios, obteve-se um total de 136 dias com concentrações que ultrapassaram o índice de $50 \mathrm{mg} / \mathrm{m}^{3}$ para os níveis de material particulado. Este número representa 14,25\% do total de dias analisados.

Do total de 136 dias identificados, 62 (45,58\%) ocorreram durante a fase pré-frontal, sob o domínio da massa polar velha. É sob domínio deste tipo de tempo, que ocorrem, portanto, a maioria dos dias de elevada concentração de material particulado. Estes dias apresentam condições atmosféricas que, em geral, se caracterizam por elevação de temperatura, fenômeno que ocorre com a tropicalização da massa polar em latitudes menores, pressão atmosférica em declínio, ventos na grande maioria soprando do quadrante $\mathrm{N}$ ou NW, possuindo, algumas vezes, segundo Sartori (1993), condições atmosféricas primordiais à formação do fenômeno da ilha de calor urbana diante das grandes amplitudes térmicas.

Em segundo lugar, com 33 dias do total analisado (24,26\%), houve o predomínio das altas pressões, sob domínio da massa polar atlântica. Esses dias foram caracterizados por pressão atmosférica alta, céu limpo, temperaturas baixas (próximas de zero no inverno), ventos dos quadrantes $\mathrm{S}$ ou $\mathrm{W}$ e calmarias.

Com a menor porcentagem dos dias de elevada concentração analisados, aparece a fase de domínio polar, embora desta vez sob efeito da massa polar continental, em apenas um dia de deposição superior a $50 \mathrm{mg} / \mathrm{m}^{3}$. Pode-se dizer que estes dias caracterizaram-se por baixíssimas temperaturas, com certeza as mais baixas do episódio, e as demais características que acompanham a atmosfera sob a fase de domínio polar. Esses dados podem ser visualizados na figura 11.

Ao mesmo tempo em que se buscou entender a distribuição média diária de material particulado entre as estações do ano, buscou-se, também, identificar se os eventos de alta concentração de mp 10 (acima de 50mg $/ \mathrm{m}^{3}$ ), nos anos de 2005 e 2006, responderam a alguma forma de controle atmosférico relacionado com a estação do ano. Estes dados são apresentados na tabela 1.

Uma das explicações para esta diferença de concentração do material particulado de acordo com a sazonalidade, é que no inverno tem-se uma estabilidade atmosférica maior que no verão, principalmente devido aos centros de alta pressão que atuam quando do domínio das massas de ar polares, fazendo com que se tenham vários dias seguidos de céu limpo, com poucos ventos. Somado a isso, a menor movimentação vertical das camadas de ar favorece a concentração dos poluentes, já que a menor incidência no inverno, em comparação ao verão, dos movimentos convectivos de ar dificultam a sua dissipação. 


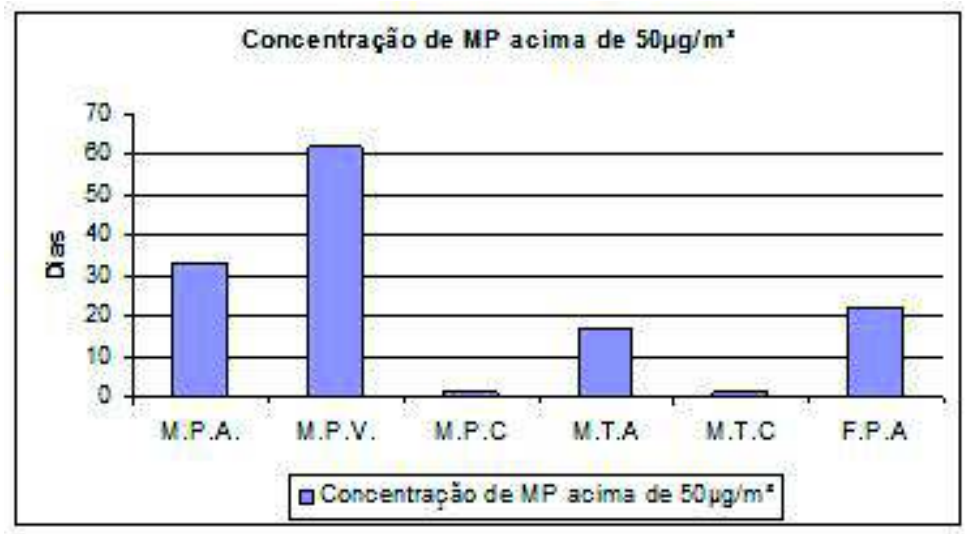

Figura 11 - Dias de elevada concentração de MP, sob domínio de Massa Polar Atlântica (MPA), Massa Polar Velha (MPV), Massa Polar Continental (MPC), Massa Tropical Atlântica (MTA), Massa Tropical Continental (MTC) e Frente Polar Atlântica (FPA).

Fonte: Estação Meteorológica de Santa Maria.

A ocorrência de dias com inversões térmicas, que se desenvolvem na atmosfera da cidade principalmente no inverno, onde a camada de ar frio fica sobre a camada de ar mais quente não permitindo os movimentos verticais de convecção, contribui também para a maior concentração e conseqüente menor dissipação dos poluentes atmosféricos.

Tabela 1 - Concentração média de material particulado para inverno e verão de 2005 e 2006

\begin{tabular}{l|l}
\hline Verão 2005 & 6 \\
Inverno 2005 & 14 \\
Verão 2006 & 4 \\
Inverno 2006 & 23 \\
\hline
\end{tabular}

Fonte: FEPAM/RS.

Da mesma forma que na presente pesquisa, em estudo realizado na cidade de Curitiba por Danni-Oliveira \& Bakonyi (2002), onde os autores procuraram verificar os índices de material particulado de forma sazonal (verão e inverno), constatou-se que as concentrações de material particulado seguiram o mesmo padrão, pois o período de inverno apresentou os índices mais elevados, também sob o domínio da massa polar velha, sendo este o tipo de tempo que precede a entrada da Frente e, portanto, favorecendo o maior acúmulo de poeiras, devido a ressuspensão das partículas de poeira que se acumularam com a escassez dos períodos chuvosos.

É importante salientar que o processo de precipitação favorece principalmente a limpeza do ar a partir das partículas grossas $\left(>2,5 \mathrm{mg} / \mathrm{m}^{3}\right)$. Contudo, as partículas finas, que são predominantemente de processos de combustão de combustíveis fósseis, continuam em suspensão. Sendo assim, devido ao processo de lavagem da atmosfera, as precipitações favorecem a decantação do material particulado e auxiliam também na dissolução dos gases (DANNI-OLIVEIRA, 2002).

Quando analisada a relação entre os dias de elevada concentração de material particulado de acordo com os dias da semana, observou-se que os finais de semana (estendendo-se até segundafeira), quando o tráfego de veículos é menos intenso, apresentaram diferenças significativas quanto ao número de dias com concentrações consideradas altas (superiores a $50 \mu \mathrm{g} / \mathrm{m}^{3}$ ) situando-se, inclusive, abaixo da média da série (figura 12).

Portanto, nos dias com menores fluxos de veículos, os poluentes da atmosfera são dispersos com maior facilidade (sempre relacionando com as condições meteorológicas vigentes), refletindo essas menores concentrações de material particulado no primeiro dia útil da semana.. 


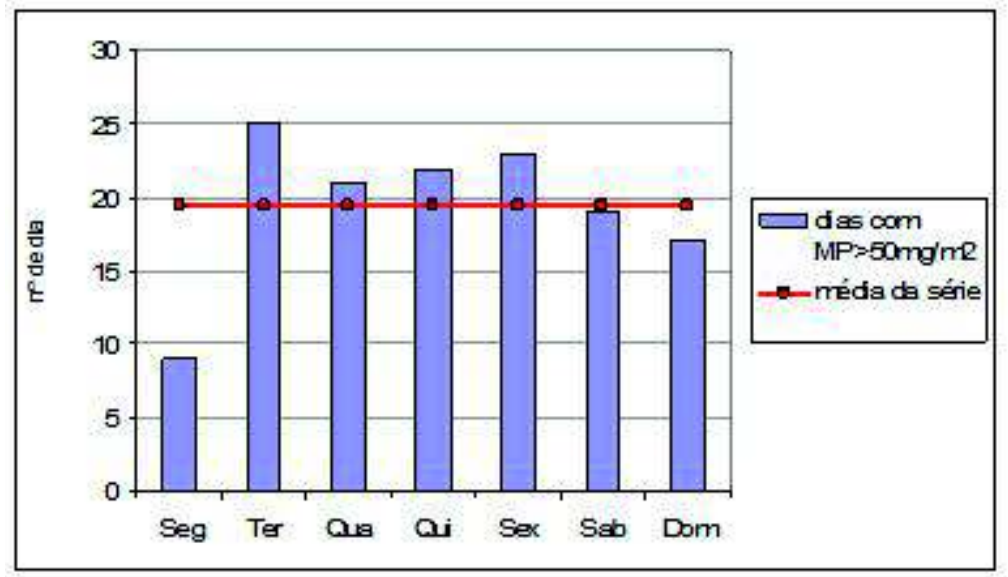

Figura 12 - Número de dias da semana de concentração de MP acima de $50 \mu \mathrm{g} / \mathrm{cm}^{3}$.

Fonte - FEPAM/RS.

\section{CONSIDERAÇÕES FINAIS}

As variáveis utilizadas para a elaboração do zoneamento ambiental do bairro Centro forneceram As variáveis utilizadas para a elaboração do zoneamento ambiental do bairro Centro forneceram diferentes respostas quando realizada a comparação das áreas tidas como de maior e menor potencial à deposição de poluentes, com o que foi coletado a campo. Neste sentido, e com base nas variáveis propostas (sentido do arruamento, presença significativa de arborização, e tráfego de veículos), grande parte das ruas e avenidas demonstraram quantidades de particulados condizentes com o que foi pré-estabelecido no zoneamento ambiental.

A investigação da relação entre as concentrações de material particulado inalável com os tipos de tempo, demonstrou a existência de uma grande correlação quanto ao número de dias de concentração acima de $50 \mu \mathrm{g} / \mathrm{m}^{3}$ com os meses de inverno para a cidade de Santa Maria.

De maneira geral, pode-se dizer que para o caso da cidade de Santa Maria, o fluxo de veículos constitui-se no principal fator de contribuição na deterioração da qualidade do ar. Ruas e avenidas de intensidade parecida quanto ao fluxo de ônibus, apresentaram diferentes concentrações de partículas depositadas, devido à influência dos outros fatores, como direção do arruamento e presença ou ausência de vegetação, uma vez que grande parte dos locais de alta concentração de particulados coincidiram com ruas de direção N-S e insignificante presença de arborização..

No tocante a atenuação das partículas de poluição que são emitidas, algumas sugestões poderiam ser utilizadas para o caso da cidade de Santa Maria, tais como:

- A conscientização e fiscalização dos motoristas para que seja efetuada a regulagem do motor.

- arborizar o mais densamente possível as ruas e avenidas que possuem maior fluxo de veículos pesados, que consomem óleo diesel, pois a emissão de partículas por esses veículos fica acrescida nas áreas onde estes aceleram, nos semáforos e nas ruas com declividades acentuadas;

- criação de barreiras verdes próximas às paradas de ônibus, quando possível, fazendo com que parte dos particulados emitidos sejam atenuados antes de entrarem em contato com as pessoas;

- para o caso específico da Rua André Marques, que obteve as maiores quantidades de poeiras, poderiam ser plantadas árvores de médio porte que captassem grande parte da poeira e fuligem emitida pelos ônibus, uma vez que na região onde foi colocada a plaqueta de coleta de material particulado as calçadas dispõem de condições para o plantio de elementos arbóreos; 
- o plantio de árvores em áreas de média a altas vertente pode ser uma forma de amenizar as quantidades de poeiras, uma vez que verificou-se grande acúmulo de partículas nessas áreas, tal como foi evidenciado na Avenida Medianeira, bem como André Marques;

- uma possível reorganização do trânsito de veículos no bairro Centro da cidade, forçando o maior uso do transporte coletivo de passageiros, com vistas a diminuir o fluxo de veículos, uma vez que diversas ruas são estreitas, facilitando que parte do que é emitido de particulados entre em contato com as pessoas que transitam em suas calçadas ,

- ainda, como medidas de conter as elevadas quantidades de poeiras na Rua André Marques, verificou-se o predomínio de árvores caducifólias, que no período de inverno perdem totalmente suas folhas, não contribuindo no sentido de melhoria da qualidade do ar. Sendo assim, sugere-se que na realização de novos plantios, a escolha priorize espécies vegetais perenes.

\section{REFERÊNCIA BIBLIOGRÁFICA}

DANNI-OLIVEIRA, I. A cidade de Curitiba/PR e a poluição do ar: implicações de seus atributos urbanos e geoecológicos na dispersão de poluentes em período de inverno. São Paulo, 1999. 330 p. Tese (Doutorado) - Universidade de São Paulo.

DANNI-OLIVEIRA, I. Considerações sobre a poluição do ar em Curitiba-pr face a seus aspectos de urbanização. RA'E GA - O Espaço Geográfico em Análise, América do Sul, 2004, p. 101-110.

DANNI-OLIVEIRA, I.M. \& BAKONYI, S.M.C. A ação da chuva, umidade relativa e velocidade do vento na dispersão do pó em suspensão no ar no Centro de Curitiba/PR. Anais do V SBCG, Curitiba, 2002 :684-692. FIGUEIRÓ, A. S. Mudanças ambientais na interface floresta cidade e propagação de efeito de borda no maciço da tijuca, Rio de Janeiro (RJ). Tese de Doutorado - Universidade Federal do Rio de Janeiro, Programa de Pós Graduação em Geografia, Rio de Janeiro, 2005. 400 p.

JACKSON, L.E. The relationship of urban design to human health and condition. Landscape and Urban Planning n.64, p. 191-200, 2003.

LOMBARDO, M. A. Ilha de calor nas metrópoles: O exemplo de São Paulo. São Paulo: Hucitec, 1985, 244p. MENDONÇA, F.A. O Clima e o Planejamento Urbano de cidades de porte médio e pequeno-proposição metodológica para estudo e sua aplicação à cidade de Londrina-PR. Tese de Doutorado em Geografia USP, 300p. 1994.

MITKIEWICZ, G.F.M. \& G.C.B. MELO. Dispersão atmosférica de poluentes em um complexo industrial siderúrgico. In: XXVIII Congresso Interamericano de Ingeniaria Sanitária Y Ambiental. Anais... Cancun, México, 2002.

NASCIMENTO, C.C. Urbanização- processo, causas e efeitos. In: e Desenvolvimento. Belém: UFPA, 1992.

Meio Ambiente:Qualidade de Vida

SARTORI, M. da G. O clima de Santa Maria, RS: Do regional ao urbano. Dissertação de Mestrado (Geografia) - Universidade de São Paulo, São Paulo, 1979.

SARTORI, M. da G. A Circulação atmosférica regional e os principais tipos de sucessão do tempo no inverno do Rio Grande do Sul, Brasil. Ciência e Natura. Santa Maria, v.8,p. 69-80., 1993.

SARTORI, M. da G. Consideração sobre a ventilação nas cidades e sua importância no planejamento urbano. Ciência e Natura. Santa Maria, 6, p.59-74, 1984.

Trabalho enviado em fevereiro de 2010 Trabalho aceito em abril de 2010 